\title{
Analytical Evaluation of Local Effects in Cylindrical Shells Testing and Design
}

\section{F. Guarracino}

Federico II University, Naples, Italy

УДК 539.4

\section{Аналитическая оценка локальных эффектов в цилиндрических оболочках при их испытаниях и проектировании}

\section{Ф. Гуаррачино}

Университет им. Федерико II, Неаполь, Италия

С использованием классического подхода Ритца и модифииированньх уравнений Доннелла выполнена простая аналитическая оценка явно аномальных результатов, полученных при испьтаниях кругльх ичлиндрических оболочек.

Ключевые слова: испытания труб, расчет предельного состояния, локальные эффекты, аналитическая оценка.

Introduction. Pipelines are used worldwide, onshore and offshore, and have now become vital components of the energy systems of all economically developed countries. Pipelines are designed to accommodate the effects of a wide range of loading conditions resulting from internal and external pressure, bending, etc., during installation and operation [1]. Pipeline design calculations have been traditionally based on the limit stress approach, but since 1996 the limit state code has been developed. The use of the limit state approach provides a more comprehensive basis for the calculation of the ultimate conditions for pipes subjected simultaneously to pressure and bending loads. The ultimate state of the pipeline deformation or loading is calculated using a model that describes the characteristic ultimate moment or strain related to the geometry and material properties of the pipe. The design factors are calculated using statistical descriptions of the scatter of test results compared to the mean values together with the statistical descriptions of the variables composing the particular model, e.g., material strength, elastic modulus, etc. In the above process, it is generally assumed that the scatter of test results from minor and usually random variations in the variables used in the model. In the case of a pipe, these variations would generally relate to the differences in the geometries of the test pipes from their corresponding nominal values, say for pipe wall thickness, or out-of-roundness.

The aim of the present paper is to provide a simple analytical evaluation of apparently anomalous results from tests on circular cylindrical shells that have been observed in the past, and can be useful to highlight the potential influence that 
these anomalies might have on the process of providing design calculation guidance using the limit state method without making resort to complex finite element analyses.

A Survey of Test Results. Usually testing a section of a circular cylindrical shell in pure bending loading envisages that the test specimen deforms according to simple bending beam theory. Primarily this implies that while the material remains elastic the application of pure bending moment will induce the maximum tensile and compressive strains that are identical in magnitude. A typical test rig for a medium diameter pipe, of about $700 \mathrm{~mm}$ diameter, is shown in Fig. 1. The test rig applies a four-point bending condition with the central section of the test pipe assumed to be subjected to bending action only, without (or at most very little) shear or axial forces.

The form of load-deformation plot from such a rig is shown in Fig. 2 for a pipe with a $D / t$ ratio of about 40 .

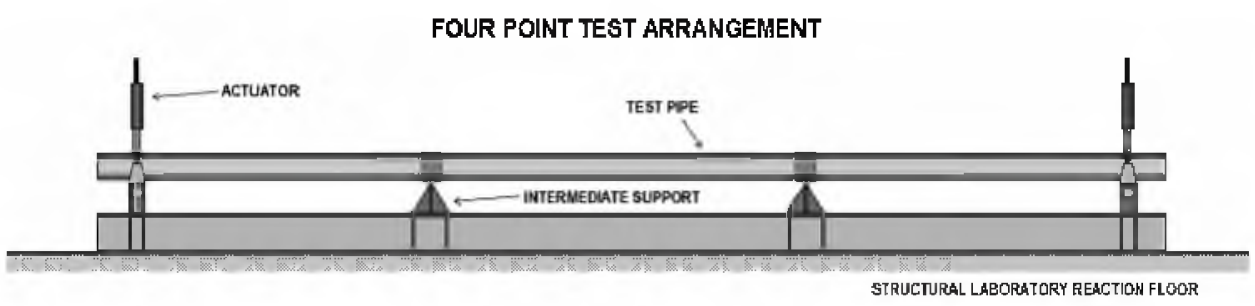

Fig. 1. Typical four-point bending test arrangement.

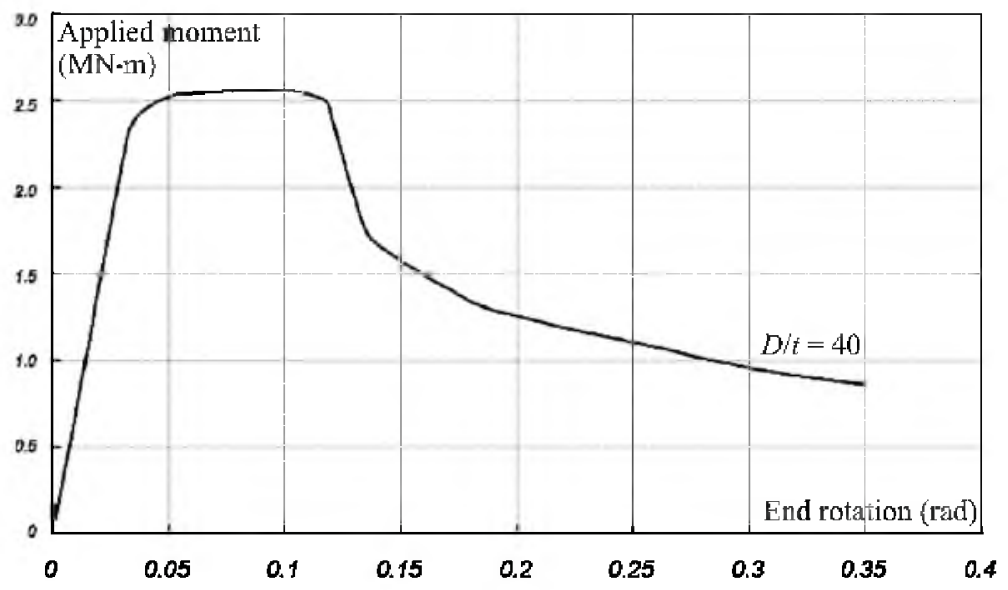

Fig. 2. End rotation vs. applied moment.

From the limit state point of view, the two relevant conditions are the maximum moment and corresponding strain, for load-controlled conditions of design, and the strain at which the reduction of load-bearing capacity first occurs, which relates to displacement-controlled design conditions. Following the attainment of that strain, as the loading is further applied, the pipe develops a very local form of buckling.

Since the pipe is assumed to be an extremely simple structural element, and the simple beam theory holds true, it has been common practice to assume that the 
axial strains have identical values in tension and compression and that the strains can be calculated directly from the curvature or the vertical displacements of the central section of the pipe. The ultimate strain values from tests in which the pipe has been loaded to the point of local buckling have usually been inferred from measurements of the deformations. Only recently have strain gauges been attached to the test pipe to measure axial strains directly.

Tests [2] were carried out on 152-mm diameter pipe to determine the minimum curvature to which the pipe could be deformed prior to local buckling occurring. An arrangement similar to that in Fig. 1 was used, and strain gauges to measure axial and circumferential strains were attached at intervals of $100 \mathrm{~mm}$ apart along the central test section. In the design of the test rig, it was assumed that a central test section of about $5 D$ would suffice to ensure that end effects due to the loading conditions would diminish to a negligible level along the major part of that section. Figure 3 shows results of the axial strain values along the top and bottom of the pipe section for two levels of the applied loading. It is evident the axial strains are fairly uniform along the length of the test section but there are significant differences in the averaged values of the compressive strains compared to the tensile strains.

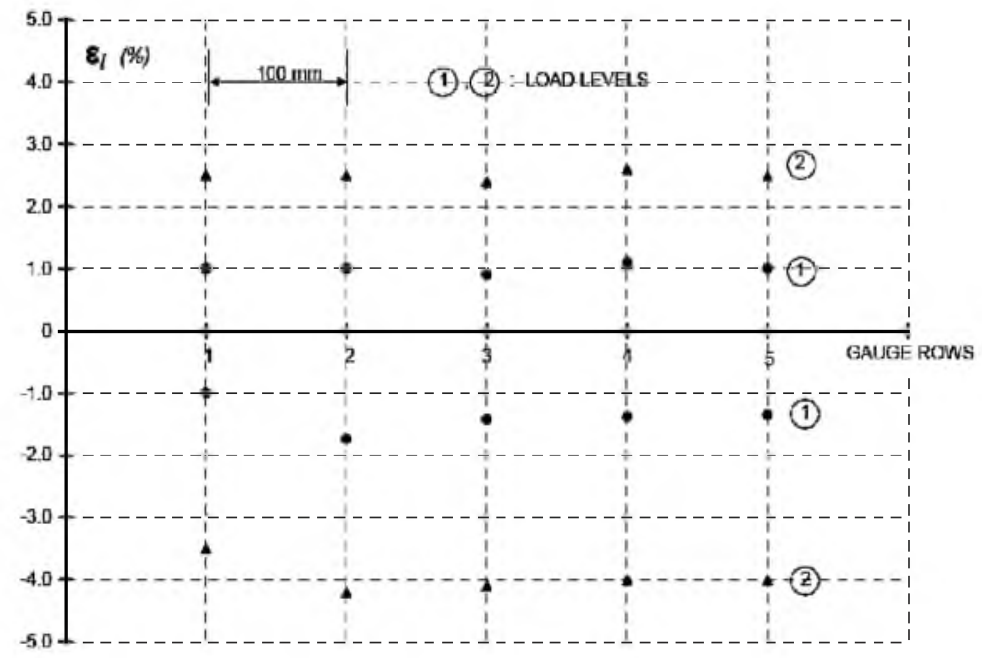

Fig. 3. Results from a 152-mm diameter pipe bend test [2].

At that time the evident anomaly between the measured strains with the expected values vs. the simple bending theory was not followed up, and even after checking that the strain gauges were correctly positioned and the instrumentation was functioning properly the cause of the anomaly was not further investigated.

Some time later, proving tests were carried out on a section of $609-\mathrm{mm}$ diameter pipes containing a thin liner made from a corrosion-resistant material [3]. The purpose of the tests was to determine accurately the level of strain to which the pipe could be bent before the liner buckled locally. The test arrangement of Fig. 1 had a loading arm $2 \mathrm{~m}$ long to create the moment in the central section of the test pipe. The test section was arranged to be $3.5 \mathrm{D}$. The load was applied to the test pipe using straight bars and loose yokes around part of the pipe circumference. A 
number of axial strain gauges were attached along the top and bottom centre lines of the pipe at intervals from the support points. The values of strain were monitored as the load values were progressively increased. Figure 4 shows plots of the values for the top and bottom gauges averaged along the test sections and plotted against the corresponding value of applied load.

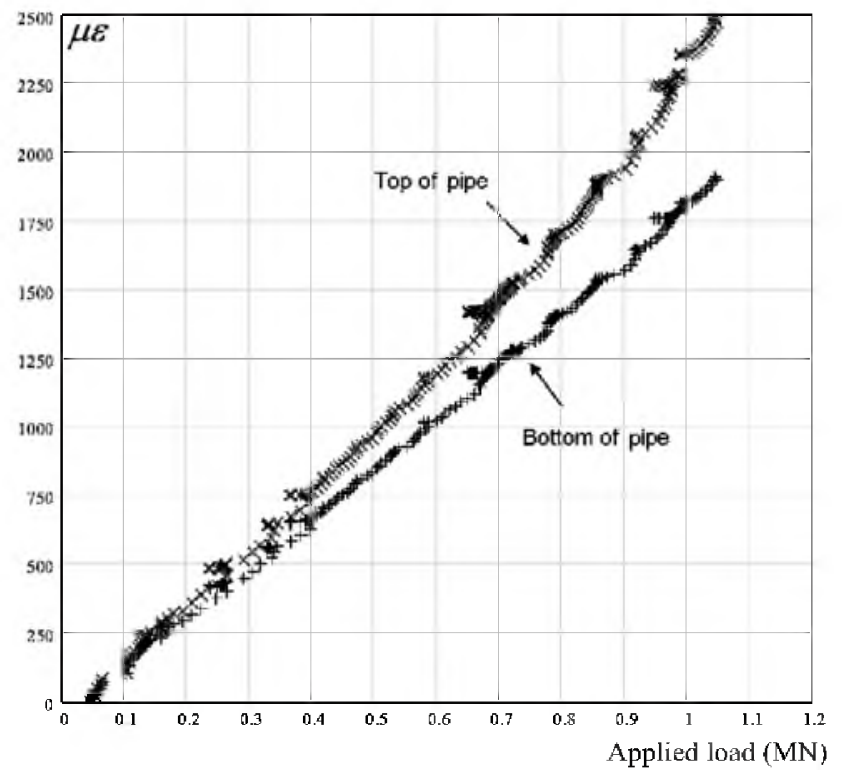

Fig. 4. Averaged strain values plotted against corresponding values of applied loading [3]: Maximum ratio of tensile to compressive averaged strains $=1.28(D=609.6 \mathrm{~mm}, t=18.9 \mathrm{~mm}, D / t=32, X 65$ material).

It is evident from Fig. 4 that there is a systematic difference between the averaged strains along the top and the bottom of the pipe. At the maximum load level, the averaged axial tensile strains were 1.28 times the corresponding averaged compressive strains.

In view of the importance of the test results in providing the allowable strain levels for the lined pipe, an investigation was made with regard to the underlying cause of the anomaly. This is described extensively in [4], with the aid of several finite element models intended to replicate the conditions in bending tests, or in pipelines that have variations in cross section and are subjected to bending with special attention paid to the constraint arrangements.

The investigation has yielded that the cause lays in the effect of the imposed ovalization applied by the saddles at the load application points. This result implies recommendation for the modification of the loading application in which the loads were applied, not through local stiffening of the pipe wall or saddles, but through the neutral axis of the pipe, as shown in Fig. 5.

The test pipe was fitted with strain gauges, as before, as well as with gauges to measure the ovality of the pipe. The values of the axial strains measured by the gauges along the test section of the pipe were quite uniform. As expected, with the modified loading and support arrangement, the averaged measured values of compressive strains agreed very closely with the corresponding values of the tensile strains. 


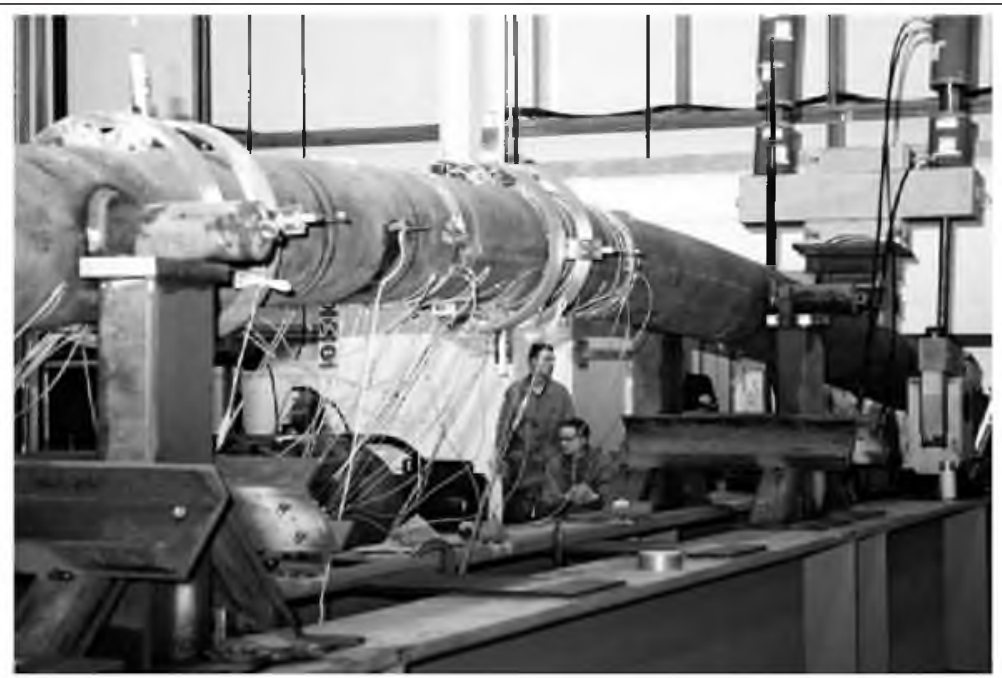

Fig. 5. Test arrangement with modified support and load application points.

Analytical Treatment of the Problem. In order to provide a simple tool to evaluate the effect of the applied loads and of the supports, reference is made to the classical Ritz approach [5] and to a modified set of the Donnell strain and curvature variations [6]. As a matter of fact, the Ritz method has been extensively used by structural engineers well through the middle of the twentieth century until it has progressively lost ground to its more versatile localized form, i.e., the finite element method. Nevertheless, many formulas of primary practical importance have been derived by this method, which still form the basis of our understanding of a large number of mechanical problems [7]. A difficulty of the Ritz method certainly consists in the extensive calculations required, but the appearance of computer algebra systems (CAS), that are software programs which allow manipulation of mathematical expressions in symbolic form, has now made possible the treatment of many problems abandoned in the past.

The advantage of the proposed procedure lies in the extreme simplicity of its final expression, which can give a meaningful physical insight into the parameters which govern the problem at hand and can also offer a first validation to subsequent three-dimensional and computationally expensive analyses.

The Donnell equations [6] have been used with a considerable degree of success for the analysis of elastic and plastic buckling of thin-walled circular cylinders. The basic assumptions at the basis of the Donnell theory have proved to be able to deal with several deformation modes with a satisfactory degree of accuracy and for this reason they can be considered to be able to represent also the cases in which loading is not symmetrical with respect to the axis of the cylinder. However, the Donnell equations are not well adapted to solution by Fourier series since some of the high-order derivatives found in the formulation sometimes lead to divergent trigonometric series. Even if in the present Ritz approach reference is naturally made to an energy expression and no differential equations are involved, a modified set of strain and curvature changes are employed.

A circular cylindrical shell is taken into consideration. With reference to an element in the middle surface of the shell, the coordinate axes are directed with the 
$x$-axis in the axial direction of the cylinder, the $y$-axis in the circumferential direction, and the $z$-axis in the radial direction, $u, v$, and $w$ are the components in the $x, y$, and $z$ directions of the displacement of a generic point. Said $\varphi$ the central angle, the strains are assumed to be

$$
\varepsilon_{x}=\frac{\partial u}{\partial x}, \quad \varepsilon_{\varphi}=\frac{1}{r} \frac{\partial v}{\partial \varphi}-\frac{w}{r}, \quad \gamma_{x \varphi}=\frac{\partial u}{r \partial \varphi}+\frac{\partial v}{\partial x} .
$$

where $r$ is the radius of the middle surface of the shell.

In calculating the expression of the strain energy, the changes of curvature of the middle surface of the shell are also required. To this scope, the following approximate expressions are assumed

$$
\chi_{x}=\frac{\partial^{2} u}{\partial x^{2}}, \quad \chi_{\varphi}=\frac{1}{r^{2}}\left(w+\frac{\partial^{2} w}{\partial \varphi^{2}}\right), \quad \chi_{x \varphi}=\frac{1}{r}\left(\frac{\partial^{2} w}{\partial \varphi \partial x}+\frac{\partial v}{\partial x}\right),
$$

and in order to evaluate the deformation induced by two opposite forces, $F$, acting along a vertical diameter at a certain section $x=0$, the components of displacement varying along the length of the cylinder are taken in the form

$$
\left\{\begin{array}{l}
u=C_{1} R \alpha e^{-\alpha x} \sum_{n=1}^{\infty} \frac{1}{n}\left[A_{n} \sin (n \varphi)+B_{n} \cos (n \varphi)\right], \\
v=C_{2} e^{-\alpha x} \sum_{n=1}^{\infty}\left[A_{n} \cos (n \varphi)-B_{n} \sin (n \varphi)\right], \\
w=C_{3} e^{-\alpha x} \sum_{n=1}^{\infty} n\left[A_{n} \sin (n \varphi)+B_{n} \cos (n \varphi)\right],
\end{array}\right.
$$

where $C_{1}, C_{2}, C_{3}, A_{n}$, and $B_{n}$ are constants that must be calculated for the case of loading at hand.

Essentially, this is the key differentiation of the present approach with respect to classical formulations which assume the change of curvature in the direction of the generatrix to be equal to zero [7]. However, as anticipated, the present assumption implies a considerable computational effort at a symbolic level to define the total strain energy by integration over the surface of the shell of the strain energy per unit area in terms of Eq. (3). Therefore, the whole operation has been performed by means of ad hoc routines written with the aid of the symbolic system MATHEMATICA ${ }^{\circledR}[8]$.

In the same manner, the equations for calculating the constants $C_{1}, C_{2}, C_{3}$, $A_{n}$, and $B_{n}$ have been first obtained by imposing the total potential energy to be a stationary value and then solved. Finally, the results have been expanded in power series. 
The end result can be summarized in the following formula, which provides the top and bottom mid-surface strain on account of the deformation induced by two opposite forces, $F$, acting along the vertical diameter at the mid-span (the formula is calculated for a circular cylindrical shell with $L>>D$ ),

$$
\varepsilon=\frac{\left(1-v^{2}\right) F r^{2}}{2 \pi^{6} E t^{4}} e^{-\beta x}\left(1-\frac{\beta^{2} x^{2}}{2}+\frac{\beta^{4} x^{4}}{24}\right),
$$

where $t$ is the thickness of the shell and $E$ and stand for the Young modulus and Poisson's ratio, respectively, and $\beta$ is given by

$$
\beta=\frac{\sqrt[4]{\left(1-v^{2}\right)}}{64 \pi \sqrt{t^{3 / r}}}
$$

It is noteworthy that the expression of what can be considered as the natural half-wavelength of the problem results proportional to the term $\sqrt{t^{3} / r}$, whereas in the case of circular shells subject to axial symmetric loading, it is proportional to $\sqrt{r t}$.

According to Eq. (4), Fig. 6 shows the value of the top and bottom strains along the axis $x$ of the pipe of Fig. 4 induced by two opposite forces of magnitude $1.118 \mathrm{MN}$.

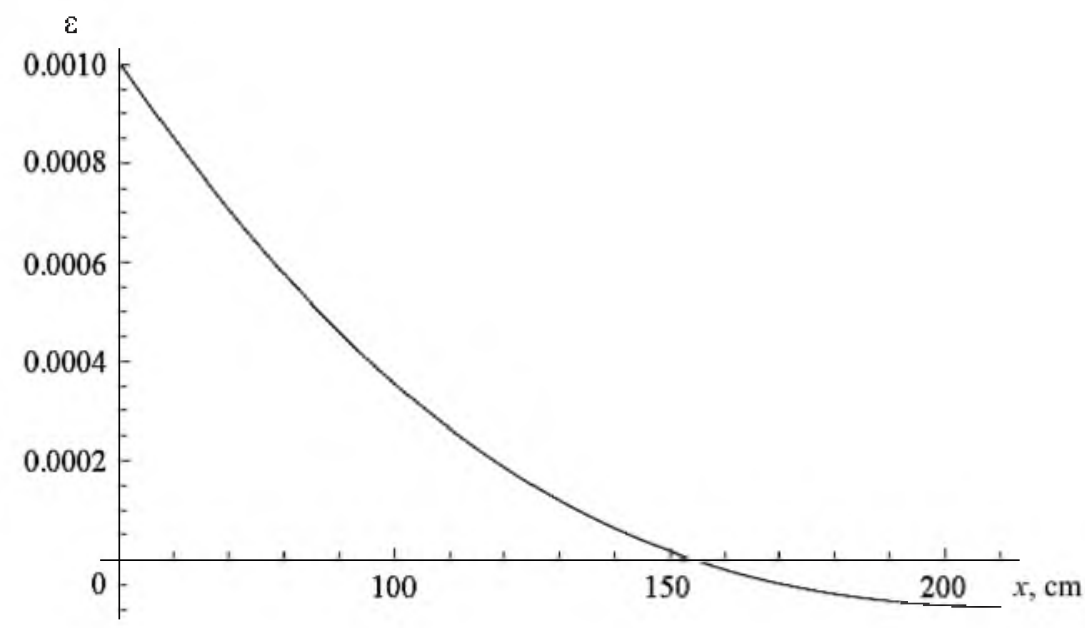

Fig. 6. Top and bottom strains induced by two opposite forces of magnitude $1.118 \mathrm{MN}$ in the pipe of Fig. $4(D=609.6 \mathrm{~mm}, t=18.9 \mathrm{~mm})$.

Thus, the proposed formula can be straightforwardly employed to evaluate the order of magnitude of the difference in top and bottom strains with regard to a tested sample of the previous Section. In fact, for the pipe characterized by $D=609.6 \mathrm{~mm}, t=18.9 \mathrm{~mm}$ and X65 material [3], for an applied load of 1.118 MN the absolute value of the top and bottom strains calculated according to the simple 
bending theory is 0.002 . Equation (4) yields the additional strain at the mid-span on account of the local deformation provoked by the concentrated loads, that is 0.000308402 (since the supports and the applied loads are not opposite, but distant $2 \mathrm{~m}$ apart, the values from each pair of forces have been halved). By adding this quantity to the tensile strain and subtracting it from the compressive one, it follows that the ratio of tensile to compressive strains is equal to 1.365 , with a difference from the measured ratio of about $7 \%$.

Conclusions. The aim of the present work has been to provide a simple analytical formulation to evaluate the effects of test arrangement on the level of apparent strain.

By means of the obtained result, the seemingly anomalous values of measured axial strain in tests can be explained quite straightforwardly. The proposed formulation also offers a physical insight into the mechanics of the problem in the fashion of many classical results still widely used in the engineering practice.

\section{Рез оме}

Iз використанням класичного підходу Рітца та модифікованих рівнянь Доннелла виконано просту аналітичну оцінку явно аномальних результатів, які отримані при випробуваннях круглих циліндричних оболонок.

1. F. Guarracino and V. Mallardo, "A refined analytical analysis of submerged pipelines in seabed laying," Appl. Ocean Res., 21, 281-293 (1999).

2. C. P. Ellinas, A. C. Walker, G. N. Langfield, and M. J. Vines, “A development in the reeling method for laying subsea pipeline," in: Proc. 1st Petroleum Technology Australian Conference, Perth (1985).

3. A. C. Walker, A. Holt, F. Guarracino, and D. Wilmot, "Test procedure for pipe and pipeline material," in: Offshore Pipeline Technology Conference, Amsterdam (2003).

4. F. Guarracino, A. C. Walker, and A. Giordano, "Effects of boundary conditions on testing of pipes and finite element modelling," Int. J. Press. Vess. Piping, in press (2008).

5. F. Guarracino and A. C. Walker, Energy Methods in Structural Mechanics, Telford, London (1999).

6. L. H. Donnell, Stability of Thin-Walled Tubes under Torsion, NACA Report No. 479 (1933).

7. S. P. Timoshenko and S. Woinowsky-Krieger, Theory of Plates and Shells, McGraw-Hill, New York (1959).

8. S. Wolfram, The Mathematica Book, Wolfram Media/Cambridge University Press, Cambridge (1999). 